\title{
Corpo, geração e identidade: a Marcha das vadias no Brasil
}

\section{Carla Gomes* \\ \& Bila Sorj**}

Resumo: Contrariamente às evocações do desaparecimento do movimento feminista, é possível identificar sua presença constante na sociedade brasileira, marcada por uma gama muito variada de identidades políticas, diferentes graus de institucionalização e diversos modos de expressão. 0 objetivo deste artigo é explorar, a partir da análise da Marcha das vadias, os contrastes e continuidades entre diferentes gerações de feministas, especialmente em relação ao modo como a questão da diversidade e inclusão de gênero, raça, sexualidade e gerações vem sendo tratada.

Palavras-chave: feminismo; Marcha das vadias; gerações; identidade.

\section{Introdução}

$\mathrm{D}$ sde o início dos anos 2000, a ideia de que o movimento feminista teria perdido a razão de ser e se tornado pouco atraente para as novas gerações de mulheres tem sido tema recorrente nos meios de comunicação. Nos discursos mais comuns da mídia, as causas apontadas para o suposto fim do feminismo são variadas e mesmo opostas. Enquanto para alguns a "crise" do movimento é explicada por seu fracasso em alcançar os objetivos almejados ou em manter sua "integridade" ideológica, para outros, é o seu extraordinário sucesso que o torna agora dispensável.

O número especial da revista Veja de 2006, intitulado "O que sobrou do feminismo", reconhece que o feminismo foi motor de profundas mudanças na vida ocidental cotidiana, mas não tendo sido capaz de desfazer as grandes desigualdades de gênero, especialmente as que perpassam a divisão sexual do trabalho, teria perdido a capacidade de mobilizar mulheres. Responsabilizado, ainda, por provocar nas mulheres um individualismo exacerbado, o feminismo estaria hoje reduzido a "uma superexposição da sexualidade" das mulheres, que reproduzem "posturas tipicamente masculinas" e se comportam como "predadoras" sexuais. ${ }^{1}$ Na maioria dos casos, porém, as muIheres que "se atiram na guerra" do sexo, diz reportagem de 2011 da revista Alfa, estariam, no fundo, ainda, à procura do "príncipe" viril. ${ }^{2}$ Por não ter logrado incutir nas mulheres um desejo coerente por igualdade, a revolução feminista, além de incompleta, teria degenerado em demandas menos relevantes ou nobres.

\author{
* Doutoranda \\ do Programa de \\ Pós-Graduação \\ em Sociologia \\ e Antropologia \\ da Universidade \\ Federal do Rio de \\ Janeiro, publicou, \\ em co-autoria com \\ Bila Sorj, "O gênero \\ da 'nova cidadania': \\ o programa \\ Mulheres da paz", \\ na revista Sociologia \\ \& Antropologia \\ (PPGSA/UFRJ), v. \\ 1, 2011 e "A Lei \\ Maria da Penha \\ e as práticas de \\ construção social \\ da violência contra \\ a mulher em um \\ juizado do Rio de \\ Janeiro", dissertação \\ de mestrado \\ em sociologia \\ Universidade Federal \\ do Rio de Janeiro \\ 2010.<carlotaufrj@ \\ gmail.com> \\ ** Professora titular \\ de sociologia da \\ UFRJ. Publicou \\ recentemente \\ "Arenas de cuidado \\ nas interseções \\ entre gênero e \\ classe social no \\ Brasil", Cadernos de \\ Pesquisa, v. 43, n. \\ 149, Mai./Ago. 2013 \\ e "Le marché de \\ l'emploi domestique \\ en Amérique latine: \\ changements et \\ permanences", in \\ Margaret Maruani \\ (ed.) Travail et genre \\ dans le monde. L'état \\ des savoirs, Paris, La \\ Découverte, 2013. \\ <sorjbila@gmail. \\ com>.
}


1. Número disponível em <http://veja.abril. com.br/especiais/ mulher_2006/p_048. html>.

2. Número disponível em <http://veja.abril. com.br/especiais/ mulher_2006/p_048. html>.

3. Disponível em <http://www.ted. com/talks/isabel_ allende_tells_tales_ of_passion>.
Por outro lado, abundam textos, debates e vídeos nas mídias em que o feminismo é considerado obsoleto, não por seu fracasso, mas porque já teria cumprido sua missão, ao proporcionar às mulheres entrada no mercado de trabalho, liberdade sexual e oportunidades iguais aos dos homens. Na melhor das hipóteses, o feminismo é uma relíquia ainda necessária às "outras" mulheres, que vivem em regiões remotas e atrasadas, longe de "nós", como se pode depreender da conferência da escritora chilena Isabel Allende, assistida via internet por quase três milhões de pessoas. ${ }^{3}$ Há também quem considere que o sucesso do feminismo foi longe demais: trouxe sobrecarga de responsabilidades às mulheres e desorientação aos homens, que não sabem mais que papel devem desempenhar, como expressam diversos blogs facilmente encontrados na internet. Assim condenado ao fracasso ou ao sucesso, o feminismo teria deixado de representar adequadamente os anseios das mulheres de hoje e perdido a legitimidade como arcabouço ideológico e prática política (ver Hawkessworh, 2006).

Essa mensagem de "crise do feminismo" reflete parcialmente um sentimento compartilhado por muitas feministas que presumem que o legado de lutas das gerações dos anos 1970 e 1980 esteja se perdendo, uma vez que os/as jovens, ao crescerem em uma sociedade que ampliou as liberdades de escolha das mulheres, teriam perdido a noção da transformação histórica das relações de gênero provocadas pelas lutas feministas dessa geração. Eliane Gonçalves e Joana Pinto apontam que a morte do feminismo

é decretada por homens e mulheres - e por razões distintas - que, no presente, encontraram os caminhos abertos por aquelas que de forma mais ou menos solitária enfrentaram a constituição de um movimento (Gonçalves \& Pinto, 2011: 36).

Em contraposição à noção de crise, algumas evidências são favoráveis aos argumentos que sustentam a vitalidade do feminismo contemporâneo. Pesquisa conduzida pela Fundação Perseu Abramo mostra que de 2001 a 2010 aumentou de 21\% para 31\% o contingente de brasileiras que se considera feminista. E metade das mulheres que se consideram ou não feministas tem visão positiva do feminismo, identificando-o com a luta por igualdade de direitos em geral (27\%), por liberdade e independência das mulheres (26\%) e por direitos iguais no mercado de trabalho (7\%). A pesquisa mostrou ainda que as mulheres jovens são as que mais se declaram feministas. Quarenta por cento das jovens entre 15 e 17 anos, a faixa etária mais jovem da amostra, se consideram feministas, seguidas das jovens de 25 a 34 anos, com 37\% de identificação, e, em último lugar, as mulheres maiores de 60 anos com 23\% (Perseu Abramo, 2010).

Outra evidência da vitalidade do movimento de mulheres pode ser detectada pelo volume de participantes envolvidas na preparação da Conferência Nacional de Políticas para as Mulheres em 2011. Estimado em 200 mil, estavam organizadas em coletivos, partidos, sindicatos e organizações comunitárias (Brasil, 2013). Provavelmente esses 
movimentos de mobilização apresentam tamanha capilaridade e estão tão descentralizados que não alcançam a visibilidade que a mídia e o público geral conseguem captar. Com certeza, muitos desses grupos não reivindicam uma identidade feminista, mas, a julgar pela pauta de reivindicações aprovadas - que inclui, por exemplo, a ampliação de construção de creches e pré-escolas públicas e a revisão da legislação punitiva do aborto -, há um forte consenso em relação às crenças e aos objetivos dos feminismos (SPM, 2011).

Neste cenário, destaca-se a organização de diversos coletivos de jovens feministas, que emergem como um segmento específico dentro do movimento, indicando que o feminismo continua relevante para as novas gerações, ainda que objeto de disputas (Zanetti, 2011; Adrião \& Méllo, 2009).

Assim, contrariamente às evocações do desaparecimento do movimento feminista, é possível identificar sua presença ativa na sociedade brasileira. Essa presença é marcada por uma gama muito variada de identidades políticas, diferentes graus de institucionalização e diversos modos de expressão. Uma das expressões do feminismo na contemporaneidade é a Marcha das vadias, transformada em objeto de estudo para entender os contrastes e as continuidades entre diferentes gerações de feministas e os desafios que essa forma de ativismo vem enfrentando na sociedade brasileira.

O estudo baseia-se em pesquisa documental e observação participante junto à organização da Marcha das vadias no Rio de Janeiro. O trabalho de campo - iniciado em fevereiro de 2013 e ainda em curso - inclui acompanhamento presencial de reuniões, debates e eventos da marcha no Rio de Janeiro. Além disso, houve o acompanhamento das páginas na internet (especialmente Facebook e blogs) da marcha em outras cidades do Brasil, como Brasília e Salvador. Finalmente, também constituíram dados de pesquisa vídeos e fotografias na internet reproduzindo as marchas de vários lugares, reportagens na mídia televisiva, debates, entre outros.

\section{Ondas ou gerações de feminismo?}

Pensar o ativismo feminista pela ótica das continuidades e persistências leva necessariamente a enfrentar o tema da periodização do movimento, que tem sido objeto de muita controvérsia. No esforço de criação de uma narrativa histórica do movimento, tornou-se comum descrevê-lo como dividido em "ondas", períodos mais ou menos delimitados no tempo e caracterizados por um tipo de concepção e prática política dominante.

Assim, para o Brasil, são apresentadas, em geral, três grandes ondas, a saber: a primeira, compreendida entre final do século XIX e a Segunda Guerra Mundial, na qual 
mulheres se organizaram em torno da conquista de direitos fundamentais como o voto, educação, ingresso em carreiras consideradas masculinas e condições dignas de trabalho. A segunda onda, deflagrada no bojo da contracultura dos anos 1960 e 1970, marca a consolidação do feminismo como movimento político e a produção teórica sobre a opressão feminina em diálogo com a militância política (Heilborn \& Sorj, 1999). "Nosso corpo nos pertence" e "o pessoal é político" foram bandeiras desta fase, frequentemente rememorada como uma espécie de "época de ouro" do feminismo. A terceira onda, mais imprecisamente localizada no final da década de 1980, marca um momento de renovação teórica e de proliferação de diversas categorias identitárias de mulheres (Piscitelli, 2002; Pinto, 2003). A unidade do feminismo, construída pelo discurso da opressão comum das mulheres nas sociedades dominantemente patriarcais, é contestada. Inaugura-se uma noção de múltiplas opressões, notadamente aquela que emerge das desigualdades raciais. Ao discurso binário simples que opunha mulheres e homens sobrepõem-se outras oposições binárias, sobretudo entre mulheres brancas e negras, do Sul e do Norte.

Todavia, a periodização do feminismo em ondas vem sendo contestada por diversas razões. Em primeiro lugar, por que a metáfora de "onda" remete a um processo de constante substituição de feminismos, no qual o anterior se esvai e é sucedido por um novo, ignorando as linhas de continuidade entre eles. Hemmings (2009) considera que a periodização em ondas afeta negativamente o pensamento feminista, fixando autoras e perspectivas a décadas específicas e enfatizando as rupturas entre as teóricas, o que termina por produzir uma valoração normativa das diferentes ondas como progresso ou perda. Bailey (1997) argumenta que a chamada terceira onda do feminismo está muito próxima da segunda para que a sua definição possa ser aceita sem restrições. A nomeação de uma "terceira onda" teria o objetivo político de, ao enfatizar e radicalizar as diferenças, conferir legitimidade aos atores que se autoidentificam com esse pretendido novo movimento.

Em segundo lugar, argumenta-se que o uso da noção de ondas implica omissões e exclusões de muitas expressões do feminismo que não se enquadram nos critérios definidos como dominantes em cada onda, conferindo, dessa maneira, uma ideia de uniformidade a um movimento que sempre teve visões dissonantes. Em terceiro lugar, o uso do termo onda cria uma aparência de neutralidade e objetividade sobre o processo de nomeação quando, na verdade, toda periodização envolve disputas de poder e lutas por reconhecimento. Nesse sentido, proclamar um momento histórico como uma "nova onda" confere poder aos seus enunciadores e valoriza a sua agenda política.

Em vez de pensar as mobilizações como quadros temporais sucessivos, optamos por abordá-las em termos de gerações (Reger, 2014), o que possibilita considerar diferentes grupos de feministas ativos simultaneamente, mantendo relações de cooperação 
e disputa. De fato, o feminismo sempre foi um movimento descentralizado, constituído de diferentes grupos de mulheres, com variadas experiências de vida e modos diversos de conceber o tema das relações de gênero, de formular ideologias e estratégias políticas.

\section{A Marcha das vadias: continuidades e mudanças no feminismo}

A Marcha das vadias é um protesto feminista que ocorre em várias cidades do mundo. Começou em Toronto, em 2011, como reação à declaração de um policial, em um fórum universitário sobre segurança no campus, de que as mulheres poderiam evitar ser estupradas se não se vestissem como sluts (vagabundas, putas, vadias). Reconhecendo nesta declaração um exemplo amplamente aceito de como a violência sexual é justificada com base no comportamento e corpo das mulheres, a primeira Slutwalk de Toronto teve como principais bandeiras o fim da violência sexual e da culpabilização da vítima, bem como a liberdade e a autonomia das mulheres sobre seus corpos. ${ }^{4}$

Desde então, por meio da rápida troca de informações proporcionada pela internet, a marcha foi organizada em diversas cidades pelo mundo. Em países de língua espanhola, o protesto ganhou o nome de Marcha de las putas ou Marcha de las vagabundas. No Brasil, São Paulo foi a primeira cidade a organizar uma marcha, em 2011, adotando o termo "vadias". A rapidez com que a marcha se disseminou pelo país e mobilizou a juventude é indissociável das possibilidades que as novas tecnologias de comunicação oferecem ao ativismo político. Já em 2012, no segundo ano do advento da Marcha das vadias, 23 cidades, de todas as regiões do Brasil organizaram protestos ${ }^{5}$ usando ferramentas como Facebook, Twitter, Youtube, blogues e emails.

Anualmente, cresce o número de cidades que sediam a marcha mantendo o espírito que originou o protesto canadense, mas definindo localmente outras reivindicações e modos próprios de organização. Todavia, apesar das diferenças locais, todas as marchas comungam dos mesmos desafios e disputas relacionadas à definição do sujeito do feminismo. Em outras palavras, em todos os lugares, a marcha se depara com a necessidade de gerenciar os critérios que definem quem o feminismo inclui e exclui.

O corpo tem um importante e duplo papel na marcha: é objeto de reivindicação (autonomia das mulheres sobre seus corpos) e é também o principal instrumento de protesto, suporte de comunicação. É um corpo-bandeira. Ao subverter o uso acusatório do termo "vadia", a marcha reivindica o termo para si e o ressignifica positivamente como "empoderamento". ${ }^{6}$ O slogan "Se ser livre é ser vadia, então somos todas vadias", comum às marchas de diversas cidades, ilustra esta ideia central. Para expressá-la, as/os participantes lançam mão de roupas sensuais, batom vermelho e topless nas

\author{
4. Conforme \\ informações do site \\ da Slutwalk Toronto: \\ <http://www. \\ slutwalktoronto. \\ com/about/how> \\ 5. Conforme \\ calendário disponível \\ em <http:// \\ marchadasvadiasbr. \\ wordpress.com/ \\ calendario/>. \\ 6. Conforme \\ informações do site \\ da Slutwalk Toronto: \\ <http://www. \\ slutwalktoronto. \\ com/about/how>
}


7. Para referências visuais da Marcha das vadias do Rio de Janeiro de 2013, há diversos vídeos disponíveis na internet. Neste link é possível encontrar um deles: <http:// www.youtube.com/ watch? $v=$ wyBAs UCUfMs>. marchas. Palavras de ordem são escritas em seus corpos, como "meu corpo, minhas regras", "meu corpo não é um convite", "puta livre", "útero laico", "sem padrão". Pelo artifício da provocação, o corpo é usado para questionar as normas de gênero, em especial as regras de apresentação do corpo feminino no espaço público. Ao mesmo tempo, o corpo é um artefato no qual cada participante procura expressar alguma mensagem que o particulariza. ${ }^{7}$

Para as gerações anteriores de feministas, a autonomia sobre o corpo aparecia atrelada às reivindicações pela descriminalização do aborto, pelo planejamento familiar e pela saúde da mulher. Para as gerações contemporâneas, o corpo assume um significado mais amplo. Ter autonomia sobre o corpo extrapola o tema do controle da reprodução e da saúde e a articulação de políticas públicas correspondentes, e passa a se referir principalmente a um modo de experimentação do corpo que, embora não prescinda de transformações na política, na cultura e nas relações interpessoais, é vivenciado como subjetivo. Assim, nas marchas, a sensualidade dos corpos é celebrada; os padrões de beleza feminina são questionados por corpos que reivindicam pelos e diferentes formatos; a menstruação é positivamente assumida. A nudez, importante instrumento de impacto nas marchas, parece condensar a um só tempo a capacidade de criticar as normas de gênero e de expressar este modo subjetivo de "libertação" do corpo.

As organizadoras da marcha do Rio de Janeiro são majoritariamente mulheres jovens, de cor branca e com nível educacional universitário. Surveys realizados com participantes da marcha nos anos de 2011 e 2012 no Rio de Janeiro confirmam que esse também é o perfil das pessoas que aderem ao movimento nas ruas (Name \& Zanetti, 2013). Nesse sentido, é possível afirmar que a Marcha das vadias guarda uma linha de continuidade com o que encontramos nos registros históricos sobre a composição social das feministas, desde o movimento das sufragettes até geração dos anos 1970, que teve presença marcante na luta pela democratização do país, na organização dos encontros nacionais feministas, na formação dos núcleos de estudos de gênero nas universidades e associações científicas e na institucionalização do feminismo no Estado.

Por outro lado, a significativa presença entre as organizadoras da Marcha das vadias e entre os participantes do protesto de rua de mulheres que reivindicam identidades não hegemônicas (LGBT) e, ainda, de homens que expressam identificação com o feminismo, mostra uma ruptura com os feminismos de décadas anteriores. O sujeito político do feminismo aparece mais diversificado e não se define exclusivamente pela identidade sexual e biológica da mulher. Isto talvez marque a principal descontinuidade com o feminismo anterior que é fortemente exclusivista em relação às mulheres. Como argumenta Maluf (2006), o X Encontro Feminista Latino-Americano e do Caribe, 
ocorrido em 2005, em Serra Negra, já marcava esses contrastes. Mulheres transexuais reivindicaram oficialmente a sua participação e o reconhecimento neste encontro como grupo identitário específico, o que foi negado pela comissão organizadora, com base, principalmente, em uma definição biológica do gênero. No encontro também havia outros grupos - as lésbicas, as negras, as indígenas e, especialmente, as jovens igualmente se apresentando enquanto grupos específicos. Ao reivindicarem um lugar político legítimo no movimento, essas disputas colocam o sujeito e a subjetividade no centro do feminismo contemporâneo.

O manifesto da Slutwalk de Toronto afirma que, embora as mulheres sejam os principais alvos de violência sexual, todos os gêneros são afetados, e enfatiza: "All genders are welcomed to Slutwalk" (grifo original). ${ }^{8}$ Entre as organizadoras da marcha do Rio do Janeiro estão mulheres transexuais muito atuantes, desde o primeiro ano do protesto na cidade. A marcha carioca autodefine-se como "transfeminista", como forma de se diferenciar de outros feminismos cujos critérios de pertencimento são mais restritos. Para as participantes da marcha, as mulheres trans compartiIham com as demais a experiência e a identidade subalterna do feminino, o que as legitima como sujeitos do feminismo. Este argumento amplia as noções de mulher e gênero, e contrasta com os argumentos que apontam a condição biológica das transexuais ou sua socialização masculina como impeditivos para seu reconhecimento como feministas.

A admissão de homens na organização da marcha carioca envolveu uma disputa mais acirrada. Algumas participantes eram contra a participação de homens nos espaços de decisão, que deveriam ser reservados exclusivamente às mulheres, incluídas aí as transexuais. Para estas organizadoras, os homens sempre poderão ameaçar a autonomia feminina, por mais pró-feministas que sejam. Algumas estavam dispostas a abrir uma exceção aos homens homossexuais, que, como as transexuais, compartilhariam com as mulheres uma identidade subalterna, o que legitimaria sua participação nos espaços de decisão. A maioria das participantes, no entanto, foi favorável à abertura da organização a todos os homens e quaisquer pessoas que compartilhem dos princípios básicos da marcha de não transfobia, não homofobia e não sexismo. Elas consideram uma missão política importante admitir os homens, não apenas nos protestos nas ruas, mas também nas esferas de discussão e decisão feministas, para, desse modo, transformá-los, mesmo que isso envolva conflito. São céticas, entretanto, que algum homem queira de fato participar regularmente das atividades de organização. Segundo suas experiências na marcha carioca, os homens aparecem apenas nas primeiras reuniões anuais e não voltam mais.

Algumas das mulheres mais atuantes da organização da marcha identificam-se como lésbicas ou bissexuais e têm experiências no movimento LGBT. Elas relatam que foram
8. <http://www. slutwalktoronto. com/about/how> 
9. Para o posicionamento da Marcha mundial das mulheres sobre a prostituição, ver: <http:// marchamulheres. wordpress. com/2012/09/21/ prostituicaoreconhecimento-eoutras-coisas/>. atraídas pelo caráter "inclusivo" e "autônomo" da marcha, além da valorização da provocação como linguagem política, esta última característica sendo comum também ao movimento LGBT, ou talvez mesmo trazida dele. Aqui também, as participantes evocam o contraste da marcha com as passeatas e movimentos feministas mais identificados com as gerações mais velhas, argumentando que, além de menos abertas à "diversidade", têm modos institucionalizados de organização, isto é, atrelados a partidos políticos, sindicatos e ONGs, e que são vistos como perniciosos. Algumas feministas mais velhas vão aos protestos da marcha, mas estão menos presentes na concepção e organização dos protestos.

A Marcha das vadias está longe de ser consensual entre as feministas, apesar da visibilidade política alcançada desde sua aparição. As forças feministas locais em disputa valorizam linguagens e objetivos políticos distintos. Os coletivos feministas mais identificados com uma proposta marxista ou "radical", bem como feministas mais velhas, tendem a considerar a marcha "despolitizada", por não problematizar a divisão sexual do trabalho, tomada como base da economia capitalista e da exploração das mulheres. A ênfase da marcha na autonomia sobre o corpo e na liberdade sexual é vista por aquelas feministas como uma abordagem que, sem a crítica marxista, resulta na mercantilização do corpo das mulheres e na banalização da sexualidade. Por exemplo, a defesa da regulamentação da prostituição pela marcha do Rio de Janeiro e outros atores é vista por algumas organizações feministas, a exemplo da Marcha mundial das mulheres, como uma leitura equivocada e individualista da autonomia feminina. ${ }^{9}$ Para esta organização, não há autonomia possível nas carreiras das prostitutas, apenas exploração patriarcal e capitalista, que nenhuma regulamentação jurídica poderá anular. O uso político da nudez e do termo "vadia" é considerado por essas outras matrizes feministas contraprodutivo enquanto estratégia política, pois além de corroborar a opção "individualista" pelo corpo, será sempre lido de maneira sexista pelos observadores e acaba aprofundando a dominação que pretende combater.

Entre os corpos do feminismo contemporâneo, observa-se a presença significativa de jovens, muitas com idades inferiores a vinte anos. A geração dos anos 1970 ingressou no feminismo na sua juventude, quando este ainda estava integrado ao movimento mais amplo de combate à ditadura. Nos anos 1980, com a abertura política, e a consolidação do feminismo enquanto movimento específico (Sarti, 2001), a geração dos anos 1970 já estava então mais madura. Muitas feministas haviam retornado de uma experiência no exílio, eram ou haviam sido casadas, já tinham experimentado a maternidade e já se encontravam inseridas no mercado de trabalho. As reivindicações mais comuns nesse período, como repartição mais justa do trabalho doméstico, serviços de creches e pré-escola, salário igual para trabalho igual, refletiam o momento do ciclo de vida dessa geração de feministas. 
Embora nessa época, bem como hoje, o afluxo de jovens para o movimento seja uma constante, as jovens que militam hoje, em contraste com as da década de 1980, reivindicam uma identidade específica dentro do feminismo, a de "jovens feministas", mais um sujeito político a reivindicar legitimidade no feminismo (Maluf, 2006). As jovens feministas questionam o "adultocentrismo" do feminismo, que reserva às mais velhas os lugares de autoridade, e reivindicam mais atenção a temas cujo impacto maior se dá na juventude, como a violência e, principalmente, o aborto (Zanetti, 2011).

A Marcha das vadias é também uma expressão deste engajamento de jovens no feminismo, que disputam com as lideranças mais velhas as relações de poder no movimento. Na organização da marcha carioca, a relação entre as mais jovens e as mais velhas ou que já transitaram por outros movimentos sociais é de colaboração e conflito. Se, por um lado, as mais jovens consideram importante aprender com as mais velhas, por outro, contestam a legitimidade que a experiência confere à hierarquia de autoridade do movimento e também veem com desconfiança os vínculos que as lideranças mais velhas mantêm com outros movimentos, posto que poderiam comprometer a autonomia política da Marcha das vadias. Sentem que o princípio de "horizontalidade", muito caro às participantes da marcha, é ameaçado pelas mais velhas, que muitas vezes têm mais poder (prestígio, confiança, experiência, recursos, redes) para convencer as menos experientes sobre o modo de fazer as coisas.

\section{Corpo e raça:}

\section{políticas de mobilizações da diferença}

O deslocamento ou a negociação de diferenças de gênero, sexualidade e geração é uma característica do feminismo contemporâneo, e se expressa na Marcha das vadias. Entretanto, um evento ocorrido na Marcha das vadias de Brasília, em 2013, revela que a linguagem política da Marcha das vadias pode ser interpretada por algumas forças como uma persistência do feminismo da segunda geração, uma vez que não contemplaria as especificidades dos corpos negros. Em outras palavras, teria dificuldade de reconhecer as diferenças de raça e classe. Essa foi precisamente a posição assumida por movimentos feministas negros que se consideraram atingidos pelo comportamento de organizadoras e militantes que expulsaram um homem negro que adentrou o espaço da manifestação.

Esta reação foi motivada a partir da intensa circulação na internet de um vídeo, realizado durante a Marcha das vadias de Brasília, em junho de 2013, que exibia a expulsão do homem. O vídeo mostrava um homem negro, portando muletas, levantando a camisa, tocando seu abdome e seu pênis por cima da bermuda, simulando prazer sexual. Em volta dele, militantes da marcha, mulheres brancas em sua maioria, usavam apitos e buzinas para denunciar a presença de um "agressor" ou "machista", como 
10. O vídeo pode ser assistido em <http:// www.youtube. $\mathrm{com} /$ watch?v= PVbxVYXFHJs>.

\section{A nota completa} está disponível em: <http:// blogueirasnegras. org/2013/06/27/ desafios-politicosfeminismo-negro/>. Ela assemelha-se, pelo teor das críticas mobilizadas, à carta que feministas negras norte-americanas endereçaram às Slutwalks locais, e que pode ser encontrada aqui: <http://www. black womensblueprint org/2011/09/23/ an-open-letter-fromblack-women-to-theslutwalk/>. tem sido de praxe em diversas marchas pelo país em situações análogas, e forçar sua saída daquele espaço, o que é chamado de "escracho". Ao que a edição do vídeo e os comentários indicam, foram vários minutos de barulho ensurdecedor e de assédio fotográfico de jornalistas e participantes sobre o homem. Algumas organizadoras, então, tentam demover as pessoas do escracho e levá-las de volta ao protesto. Enfim, abre-se uma brecha na multidão, e o homem se afasta, deixando visível ao espectador sua perna amputada. Irritado, ele atira sua muleta contra um carro. ${ }^{10}$

Imediatamente, por meio de uma enxurrada de textos em blogs, comentários no Twitter, Facebook e sites de movimentos sociais, feministas negras se levantaram contra as organizadoras da marcha de Brasília, acusando-as de racismo. Texto publicado no blog Blogueiras Negras assim se expressa sobre o referido episódio:

[...] Alguém explica isso: como mulheres em grande parte brancas e universitárias, hostilizando e perseguindo um homem negro, pobre, deficiente e com problemas mentais pode ser igual a luta contra o machismo? Sério que ele personifica o inimigo?

[...] Nós, Pretas Candangas, estivemos em uma reunião de organização da Marcha das vadias no ano passado [...] a convite de algumas organizadoras. Junto com outras mulheres negras presentes, posicionamos nossas divergências quanto à marcha. Divergências de princípio. Falamos sobre como temos de enfrentar cotidianamente a sociedade hegemônica para mostrar que não somos vadias, que não temos a "cor do pecado". Falamos que não queremos reivindicar o direito de ser vadias, mas sim de ser médicas, advogadas, doutoras. O fato ocorrido dentro da marcha este ano reforça as diferenças.

[...] Uma coisa que dificilmente entra na cabeça de várias de nossas interlocutoras é a necessidade que nós, mulheres negras, temos de defender a existência dos homens negros. Não falamos apenas do pai opressor. Pela nossa história, convivemos também com os registros do avô escravizado, do pai encarcerado, do irmão desempregado, do filho executado, todos pagando o preço de ser tidos como vadios!

[...] Se a nota da organização da Marcha das vadias chegar, servirá apenas como mais um registro importante para nossas reflexões sobre essa instável parceria entre feministas brancas e mulheres negras. ${ }^{11}$

A nota das organizadoras da Marcha das vadias Brasília apresenta uma retratação, mas também se ressente da deslegitimação de seu modo de protesto e organização por parte desse coletivo de mulheres negras:

[...] Esse foi também o grande erro de ação da Marcha das vadias do DF [...] a dificuldade na desconstrução de privilégios que fazem 
parte do cotidiano de muitas de nós, o que muitas vezes nos leva a reproduzir as opressões que buscamos combater. Considerando que aquele homem também é constantemente oprimido - pela sua classe, sua situação de rua, sua saúde debilitada e sua cor - não poderíamos agir de maneira a igualá-lo a um agressor qualquer.

Algumas de nós - mulheres negras - nos sentimos profundamente magoadas pelas maneiras antifeministas com que outras companheiras negras nos acusaram, questionando não apenas nosso feminismo como também nossa militância e nossa composição dentro da marcha. $^{12}$

Esse evento mostra que a identidade de raça/cor pode ser construída de diferentes formas em sua relação com no feminismo. Movimentos de mulheres negras interpretam o evento como um sinal de profunda divisão entre as feministas, segundo a qual a Marcha das vadias, formada majoritariamente por mulheres brancas de classe média, não teria como incorporar as "especificidades" da mulher negra. Elas criticam a pretensão da marcha de falar pelas mulheres como categoria universal e afirmam a política da diferença e das identidades. Por outro lado, mulheres negras feministas integrantes da Marcha das vadias resistem à divisão do feminismo em linhas raciais e reafirmam a capacidade da marcha de representá-las. A política de identidades opera, assim, um duplo movimento: ao construir divisões, opondo as "mulheres brancas" às "mulheres negras", promove também aproximações, na medida em que essa oposição é contestada por mulheres negras que se sentem representadas pela Marcha das vadias. Por exemplo, as organizadoras da Marcha das vadias em Salvador, ao mesmo tempo em que afirmam as desigualdades específicas sofridas pelas mulheres negras, reconhecem que todas as mulheres são, de alguma maneira, vítimas de padrões de feminilidade impostos pela sociedade. Desse modo, o gênero se constitui como categoria política central que permite a inclusão na Marcha das vadias de todas as mulheres. As organizadoras da Marcha das vadias de Salvador, muitas delas negras, afirmam em seu manifesto:

No nosso país e principalmente no estado da Bahia, independente de raça, classe, etnia ou religião, as mulheres sofrem algum tipo de violência. Deve-se ressaltar a sexualização e a sensualização das mulheres negras que são exibidas como perfis nacionais na "mulata quente do samba", na "negra fogosa", na "globeleza" etc. [...] São contra esses dados que convidamos a sociedade baiana para lutar [...]. Também é pelo padrão branca-jovem-hétero que a sociedade machista [impõe], cerceando a liberdade e a diversidade de quem quer e deve ser o que se é. ${ }^{13}$

Nos dilemas internos do feminismo contemporâneo, para lidar com o estatuto da diferença e da identidade parece haver dois cenários em curso. O primeiro é a afirmação política pela oposição identitária, que investe na demarcação de diferenças raciais,
12. A nota completa, publicada em 2 de julho de 2013, está disponível em: <http:// marchadasvadiasdf. wordpress.com/>.

13. A íntegra do
manifesto está
disponível em:
<https://groups.
google.com/
forum/\#!topic/
coletivo-de-direitos-
humanos-cut/_x_
Tp26osGc>.

Tp26osGc>. 
geracionais, de classe, gênero e/ou sexualidade. No plano teórico, esta posição encontrou expressão no conceito de interseccionalidade, que busca apreender a interação dessas diferenças na produção de desigualdades e reconhecer as vozes subalternas do feminismo (Crenshaw, 1989). A defesa de um "feminismo interseccional" e "políticas interseccionais" é recorrente nos discursos dessa matriz feminista. Jovens feministas, mulheres negras e, mais recentemente, "mulheres da periferia" são exemplos de identidades que fortalecem este modelo.

O segundo cenário é o de reconhecimento das diferenças a serviço de uma política de coalizão (Harding, 1992; Mohanty, 2003). As diferenças são mobilizadas para uma definição mais universal da identidade feminista, sem se sobrepor a ela. Mulheres e homens transexuais, homens feministas, mulheres lésbicas e integrantes negras da Marcha das vadias mobilizam marcadores de diferença e experiências de desigualdade para alargar a identidade comum feminista. No plano teórico, este posicionamento encontra referências na teoria queer, que busca desconstruir a naturalidade das diferenças e das identidades (Butler, 2008). É importante notar que os dois caminhos não parecem ser, a princípio, excludentes, visto que enquanto buscam espaços de militância que privilegiam a coalizão da diversidade, muitos desses atores atuam concomitantemente em movimentos segmentados, como o movimento de transexuais, de lésbicas e de mulheres negras, onde buscam tratar de questões "específicas".

\section{Considerações finais}

Diferentemente do que comumente se evoca, o feminismo brasileiro contemporâneo parece conter um grande dinamismo que se manifesta na ampla diversidade de suas expressões coletivas e das relações que mantêm entre si, ora marcadas por cooperação ora por conflitos.

A Marcha das vadias constitui um desses movimentos que permite explorar as relações de continuidade e mudanças com outras gerações de feministas. Em linhas gerais, é possível concluir que a reivindicação de autonomia das mulheres face às convenções de gênero, notadamente no que se refere às disposições corporais, permanece central nos movimentos feministas. Todavia, o novo repertório cultural com que as novas gerações se defrontam, sobretudo diante da expressiva presença do movimento LGBT no cenário político brasileiro, desafia algumas convicções feministas clássicas, como a exclusividade das mulheres como sujeitos políticos do feminismo.

O debate sobre a legitimidade de incorporar homens e transexuais na organização da Marcha das vadias e as negociações que resultaram dessa demanda, indicam 
uma mudança significativa e tensa em relação às concepções feministas das gerações dos anos 1970 e 1980. A chamada oposição binária entre gênero e sexo, que servia de base para a definição do sujeito do feminismo, encontra-se confrontada com uma concepção na qual gênero, sexo, prática sexual e desejo flutuam independentemente, de modo a produzir uma multiplicidade de identidades que se definem como feministas.

A visibilidade do movimento negro ensejou a problematização da questão racial, que foi pouco abordada pelos feminismos anteriores. Justamente na Marcha das vadias, que confere ao corpo centralidade política, estética e de expressão pessoal, a cor/ raça tornou-se um tema recorrente de debates e disputas. Da mesma forma como a categoria "mulher" passou a ser percebida como excludente, a Marcha das vadias vem sendo criticada por movimentos de mulheres negras, que se sentem marginalizadas por um ativismo que expressaria a posição social privilegiada das mulheres brancas. Todavia, tal interpretação, como vimos, é contestada por mulheres negras que se sentem representadas pela Marcha das vadias e que resistem a adotar uma política feminista que repousa na chave binária, que opõe mulheres de raças e classe sociais distintas.

A existência dessas controvérsias ilustra a complexidade dos feminismos no tempo presente e possivelmente abrirá novos caminhos e direções para o movimento no futuro.

Abstract: Contrary to evocations about the demise of the feminist movement, it is possible to identify its constant presence in Brazilian society, characterized by a wide range of political identities, different degrees of institutionalization and various ways of expression. The aim of this paper is to explore, based on the analysis of the Brazilian Slutwalk, the contrasts and continuities between different generations of Feminists, especially in relation to how the issue of diversity and inclusion of gender, race, sexuality and generations has been treated.

Key words: feminism, Slutwalk, generations; identities.

\section{Referências}

AdrIÃo, Karla Galvão; MÉLLo, Ricardo Pimentel. As jovens feministas: sujeitos políticos que entrelaçam questões de gênero e geração? Anais do XV Encontro Nacional da Abrapso, Maceió, 2009.

BAILEY, Cathryn. Making waves and drawing lines: the politics of defining the vicissitudes of feminism. Hypatia 12 (3),1997. 
BRASIL. Presidência da República. Secretaria de Políticas para as Mulheres. Plano Nacional de Políticas para as Mulheres. Brasília: Secretaria de Políticas para as Mulheres, 2013.

BUTLER, Judith. Problemas de gênero: feminismo e subversão da identidade. 2. ed. Rio de Janeiro: Civilização Brasileira, 2008.

CRENSHAW, Kimberlé W. Demarginalizing the intersection of race and sex: a black feminist critique of antidiscrimination doctrine, feminist theory and antiracist politics. University of Chicago Legal Forum, 1989, pp. 139-67.

GonÇALVES, Eliane; PINTO, Joana Plaza. Reflexões e problemas da "transmissão" intergeracional no feminismo brasileiro. Cadernos Pagu, 36, 2011, pp. 25-46.

HARDING, Sandra. Subjectivity, experience and knowledge: an epistemology from/for rainbow coalition politics. Development and Change, 23, 1992, pp. 175-193.

HAWKESSWORH, Mary. A semiótica de um enterro prematuro: o feminismo em uma era pós-feminista. Estudos Feministas 14 (3). Florianópolis, 2006, pp.737-764.

Hemmings, Claire. Contando estórias feministas. Estudos Feministas 17(1). Florianópolis, 2009, pp. 215-241.

HeIlborn, Maria Luiza; SorJ, Bila. Estudos de gênero no Brasil. In: Micelı, Sérgio (Org.). O que ler na ciência social brasileira (1970-1995). São Paulo: Sumaré/Anpocs, v. 2, 1999, p. 183-221.

Maluf, Sônia W. Políticas e teorias do sujeito no feminismo contemporâneo. Anais do Seminário Internacional Fazendo Gênero 7, Santa Catarina, 2006.

MoHANTY, Chandra T. Feminism without borders: decolonizing theory, practicing solidarity. Durham; London: Duke University Press, 2003.

NAME, Leonardo; ZANETTI, Julia. Meu corpo, minhas redes: a Marcha das vadias do Rio de Janeiro. Anais do Encontro Nacional da Associação Nacional de Pós-Graduação e Pesquisa em Planejamento Urbano e Regional, Recife, 2013.

Perseu Abramo, 2010. Mulheres brasileiras e gênero nos espaços público e privado. Pesquisa de opinião pública. Agosto de 2010.

PINTO, Céli Regina J. Uma história do feminismo no Brasil. São Paulo: Fundação Perseu Abramo, 2003.

Piscitelli, Adriana. Recriando a (categoria) mulher? In: AlgRANTI, L. (Org.). A prática feminista e o conceito de gênero. Textos Didáticos, n. 48. Campinas: IFCH/Unicamp, 2002, p. 7-42. 
REger, Jo. Debating US contemporary feminism. Sociology Compass 8(1), 2014, pp. 43-51.

SARTI, Cynthia A. Feminismo e contexto: lições do caso brasileiro. Cadernos Pagu 16, 2001, pp.31-48.

SPM (Secretaria de Políticas para as Mulheres da Presidência da República). Anais da III Conferência Nacional de Políticas para as Mulheres. Autonomia e igualdade para as mulheres, 12 a 15 de dezembro de 2011, Brasília - DF.

ZANETTI, Julia Paiva. Jovens feministas do Rio de Janeiro: trajetórias, pautas e relações intergeracionais. Cadernos Pagu 36, 2011, pp. 47-75. 
